\title{
Benefits of switching from latanoprost to preservative-free tafluprost eye drops: a meta-analysis of two Phase IIlb clinical trials
}

This article was published in the following Dove Press journal:

Clinical Ophthalmology

15 March 2016

Number of times this article has been viewed

\author{
Hannu Uusitalo' \\ Evgeniy Egorov ${ }^{2}$ \\ Kai Kaarniranta ${ }^{3}$ \\ Yuri Astakhov ${ }^{4}$ \\ Auli Ropo ${ }^{5}$ \\ On behalf of the Switch \\ Study Tafluprost Study \\ Groups
}

'Department of Ophthalmology, SILK, University of Tampere, Tampere University Hospital, Tampere, Finland;

${ }^{2}$ Department of Ophthalmology,

The Russian National Research

Medical University, Moscow, Russia;

${ }^{3}$ Department of Ophthalmology,

University of Eastern Finland, Kuopio

University Hospital, Kuopio, Finland,

${ }^{4}$ Department of Ophthalmology, First Pavlov State Medical University of St Petersburg, Saint Petersburg, Russia, ${ }^{5}$ Global Medical Affairs, Santen Oy,

Tampere, Finland
Correspondence: Hannu Uusitalo Department of Ophthalmology, SILK, University of Tampere, ARVO B229,

Tampere 33014, Finland

Tel +358 $40190 \quad$ I2I 4
Email hannu.uusitalo@uta.fi

Introduction: Glaucoma patients frequently exhibit ocular surface side effects during treatment with prostaglandin eye drops. The present work investigated whether glaucoma patients suffering from signs and symptoms of ocular surface disease while using preserved latanoprost eye drops benefited from switching to preservative-free tafluprost eye drops.

Patients and methods: The analysis was based on 339 glaucoma patients enrolled in two Phase IIIb trials. The patients were required to have two symptoms, or one sign and one symptom of ocular surface disease at baseline, and at least 6 months preceding treatment with latanoprost eye drops preserved with benzalkonium chloride. All eligible patients were switched from latanoprost to preservative-free tafluprost for a total of 12 weeks. Ocular symptoms and ocular signs were evaluated at baseline and at 2 weeks, 6 weeks, and 12 weeks after commencing treatment with tafluprost. Intraocular pressure (IOP), drop discomfort, and treatment preference were evaluated to investigate the clinical efficacy and patient-related outcomes.

Results: After 12 weeks of treatment with preservative-free tafluprost, the incidences of irritation/burning/stinging, foreign body sensation, tearing, itching, and dry eye sensation had diminished to one-third of those reported for preserved latanoprost at baseline. The incidences of blepharitis and corneal/conjunctival fluorescein staining had in turn decreased to one-half of those reported for preserved latanoprost. Severity of conjunctival hyperemia was halved during treatment with preservative-free tafluprost, and there was significant improvement in tear break-up time and tear production. A further reduction in IOP $(\sim 1 \mathrm{mmHg})$ was seen with preservative-free tafluprost compared with preserved latanoprost. Drop discomfort was alleviated during preservative-free tafluprost treatment, and an outstanding majority of patients (72\%) preferred preservative-free tafluprost over preserved latanoprost.

Conclusion: This meta-analysis confirmed that IOP remained at the same level after replacing benzalkonium chloride-preserved latanoprost eye drops with preservative-free tafluprost eye drops. Preservative-free tafluprost significantly decreased the symptoms and signs of ocular surface disease and outrated latanoprost in drop comfort and treatment preference.

Keywords: Taflotan ${ }^{\circledR}$, preserved latanoprost, Xalatan ${ }^{\circledR}$, ocular surface disease, ocular symptoms and signs, IOP, patient-related outcome

\section{Introduction}

Several studies have recently illustrated that a large number of glaucoma patients using topical drugs suffer from concomitant ocular surface disease. ${ }^{1-3}$ According to those studies, as much as half of these patients appear to encounter dry eye symptoms. It has further been demonstrated that the preservative - mostly benzalkonium chloride (BAC) - is the causative agent leading to the symptoms of dry eye. Thus, the adverse preservative effects constitute a significant clinical problem in the treatment of glaucoma. 
BAC is most commonly used with concentrations ranging from $0.004 \%$ to $0.02 \%$ in the antiglaucoma medications; within this range, it is toxic in a dose-dependent manner. BAC has been shown to have direct toxicity to various tissues of the ocular surface and causes adverse effects, such as conjunctival hyperemia, punctate keratopathy, and epithelial erosions. In addition, accumulation of signs and symptoms, such as irritation/burning/stinging, itching, foreign body sensation, tearing, and dry eye sensation, has been reported. ${ }^{4,5}$ Glaucoma drugs that contain a preservative have been incriminated in reducing the number of goblet cells, increasing the subepithelial collagen deposition, expanding the substantia propria with an infiltrate of chronic inflammatory cells, and even exhibiting a proapoptotic effect in the conjunctiva. ${ }^{6-11}$ The use of antiglaucoma drugs in general and BAC-containing drugs particularly has been directly linked to the failure of glaucoma surgery. ${ }^{9,12}$ Tafluprost $0.0015 \%$ ophthalmic solution (Taflotan ${ }^{\circledR}$, Saflutan ${ }^{\circledR}$; Santen, Osaka, Japan) was the first preservative-free prostaglandin medication developed for the treatment of glaucoma; it has a proven preclinical and clinical intraocular pressure (IOP)-lowering efficacy. ${ }^{13-19}$ Tafluprost is a prodrug of synthetic analog of prostaglandin $\mathrm{F}_{2 \alpha}$ and acts on prostaglandin $\mathrm{F}$ prostanoid receptors with high affinity and selectivity. The pharmacological mechanism of action of tafluprost is analogous to that of latanoprost $0.005 \%$ (Xalatan ${ }^{\circledR}$; Pfizer, Inc., New York, NY, USA) and travoprost $0.004 \%\left(\operatorname{Travatan}^{\circledR}\right.$; Alcon, Inc., Fort Worth, TX, USA) ophthalmic solutions, whereas bimatoprost $0.03 \%$ (Lumigan $^{\circledR}$; Allergan, Inc., Irvine, CA, USA) can be regarded as both a prostaglandin prodrug and a prostamide.

The aim of this paper is to present the meta-analysis results of two independent clinical Phase IIIb studies, among which the first study was published as a full paper and the second published only in the local language..$^{20,21}$ Both studies in question had an identical design and recruited glaucoma patients who had developed signs and symptoms of ocular surface disease during treatment with preserved latanoprost eye drops (containing a high $0.02 \%$ concentration of BAC). The preserved latanoprost eye drops were switched to preservative-free tafluprost eye drops after the baseline visit for a period of 12 weeks. Especially, ocular signs and symptoms, IOP, drop discomfort, and patient preference were evaluated and pooled across the studies for the purpose of this meta-analysis.

\section{Patients and methods}

The meta-analysis was based on two independent, openlabel, multicenter, Phase IIIb clinical studies: one performed in Finland, Sweden, and Germany during 2008 and the other in Russia during $2010 . .^{20,21}$ A total of 158 patients from 12 centers were enrolled in the first study, whereas 185 patients from seven centers were enrolled in the second study. Both studies adopted an essentially identical study protocol with the exception that impression cytology of the conjunctiva was performed only in the first study. ${ }^{20}$ Openlabel designs were used, since the preservative-free tafluprost eye drops were commercially available only in unit dose dispensers and not in conventional multidose bottles as with preserved latanoprost.

The two studies were completed in compliance with the Good Clinical Practice guideline of the International Conference on Harmonization and the Declaration of Helsinki. The study protocols were approved by the local Independent Ethics Committees and the National Competent Authority. Written informed consent was provided by each patient before inclusion in the study.

Patients of either sex aged 18 years or older were screened for the two studies. Eligible patients were required to have a diagnosis of ocular hypertension $(\mathrm{OH})$ or open-angle glaucoma (OAG) in either eye or both eyes and at least 6 months preceding instillation of preserved latanoprost eye drops. OAG comprised primary OAG and pseudoexfoliative glaucoma (PEX). The presence of at least 1) two symptoms or 2) one sign and one symptom of ocular surface disease was imperative for all patients at the screening visit (Table 1). Additional inclusion criteria were best-corrected visual acuity score of +0.6 logarithm of the minimum angle

Table I Eligibility (abnormality) criteria for the symptoms and signs of ocular surface disease in the individual studies

\begin{tabular}{lll}
\hline Ocular symptom & Grading & Eligibility criteria \\
\hline Irritation/burning/stinging & $0-4^{\mathrm{a}}$ & At least grade 2 \\
Foreign body sensation & $0-4^{\mathrm{a}}$ & At least grade 2 \\
Tearing & $0-4^{\mathrm{a}}$ & At least grade 2 \\
Itching & $0-4^{\mathrm{a}}$ & At least grade 2 \\
Dry eye sensation & $0-4^{\mathrm{a}}$ & At least grade 2 \\
\hline Ocular sign & Unit/grading & Eligibility criteria \\
\hline Fluorescein tear break-up time & Seconds & $<$ I0 seconds \\
(tBUT) & & \\
Corneal fluorescein staining & $0-\mathrm{V}^{\mathrm{c}}$ & At least grade I \\
Conjunctival fluorescein staining & $0-\mathrm{X}^{\mathrm{d}}$ & At least grade II \\
Blepharitis & $0-3^{\mathrm{e}}$ & At least grade I \\
Conjunctival hyperemia & $0-4^{\mathrm{f}}$ & At least grade I \\
Tear production & $\mathrm{mm}^{\mathrm{g}}$ & $\leq$ I0 mm \\
\hline
\end{tabular}

Notes: For ocular symptoms, the treated eyes were considered together, whereas the signs were evaluated by eye (and the analyses were based on the eye with the worse grading). ${ }^{a} 0=$ none, $I=$ trace, $2=$ mild, $3=$ moderate, and $4=$ severe. ${ }^{b} S$ lit lamp microscope. ${ }^{\mathrm{C}}$ Oxford grading scale $(0-\mathrm{V})$. ${ }^{\mathrm{d}} \mathrm{Combined}$ nasal $(0-\mathrm{V})$ and temporal $(0-\mathrm{V})$ score by $O x f o r d$ grading scale. ${ }^{e} 0=$ none, $I=$ mild, $2=$ moderate, and $3=$ severe. 'Redness scale with reference photographs (half grades allowed); $0=$ none, I= mild, $2=$ moderate, $3=$ severe, and $4=$ very severe. ${ }^{8}$ Schirmer's test. 
of resolution ( $\log$ MAR) or better in both eyes (based on early treatment diabetic retinopathy study eye charts) and willingness to follow instructions and provision of a written informed consent.

Ocular exclusion criteria were anterior chamber angle $<2$ (by gonioscopy and Shaffer's classification), corneal abnormality or other condition (such as prior refractive eye surgery) preventing reliable applanation tonometry, IOP $>22 \mathrm{mmHg}$ (at $3 \mathrm{pm}$ with preserved latanoprost), use of preserved artificial tears during the past 2 weeks, diagnosis of angleclosure glaucoma or secondary glaucoma other than PEX, contraindication or hypersensitivity to tafluprost, glaucoma filtration surgery or any other ocular surgery (including laser procedures) within 6 months prior to screening, and use of contact lenses. Systemic exclusion criteria were pregnancy or lactation, unwillingness to avoid pregnancy, and current alcohol or drug abuse. In addition, any ocular or systemic condition (such as aphakia or diabetes) that could put the patient at risk, confound the results, or interfere with the patient's participation in the study was a cause of exclusion. Participation in another investigational drug (or device) study during the past 30 days was also prohibited.

Standard ophthalmic procedures were used to investigate the study patients. Ocular symptoms and signs were queried/ assessed using the scales and tests mentioned in Table 1. IOP was measured (in $\mathrm{mmHg}$ ) by applanation tonometry. Drop discomfort was evaluated using a four-grade scale: no, mild, moderate, or severe discomfort. Quality-of-life (QoL) assessments utilized a validated questionnaire for comparing the tolerability of ophthalmic medications (COMTol). ${ }^{22}$ The questionnaire was managed by an interviewer at each study clinic. Patients' preference for the treatment options (preserved latanoprost or preservative-free tafluprost) was evaluated within this questionnaire using a three-grade scale: latanoprost, tafluprost, or neither. Adverse events were queried, visual acuity (logMAR score) and visual field were tested, and biomicroscopic and ophthalmoscopic findings were evaluated in order to further assess the safety of the patients.

Both studies accommodated a total of five visits to the clinic. The treatment period included a consolidated screening/baseline visit and subsequent visits 2 weeks, 6 weeks, and 12 weeks after commencing once-daily treatment with preservative-free tafluprost in the evening of the baseline visit. A post-study visit was scheduled 1-3 weeks after the cessation of tafluprost treatment at 12 weeks. All the aforementioned examinations were done at the baseline visit. The examinations were renewed at the 2-week, 6-week, and 12-week visits, apart from visual field test and ophthalmoscopy (redone at 12 weeks only). At the poststudy visit, in turn, all examinations were done besides the assessment of ocular symptoms and signs, drop discomfort, and treatment preference (QoL). All study procedures were performed at approximately the same time of the day during the course of the study; for example, IOP was measured invariably at $3 \mathrm{pm} \pm 1$ hour.

Sample size calculations were done for both studies. An occurrence of $40 \%-50 \%$ was anticipated for a single ocular symptom or sign (such as foreign body sensation) at baseline. In other words, $40 \%-50 \%$ of the patients were expected to experience at least mild foreign body sensation at the baseline visit. A decrease of $10 \%$ in the incidence of a single symptom or sign was then regarded as a reasonable basis for sample size calculations. Making use of this assumption and McNemar's test (with a two-sided type I error of 5\% and a power of $80 \%$ ), at least 150 eligible patients needed to be enrolled in each study. The actual sample sizes satisfied this criterion (Table 2) and added up to a total of 343 patients included in this meta-analysis.

Individual data were available for both studies. The results were summarized at baseline (preserved latanoprost) and at 6-week and 12-week visits (preservative-free tafluprost). A statistical model including fixed effects for

Table 2 Demographic characteristics of the patients at baseline in the individual studies and the entire meta-analysis cohort

\begin{tabular}{|c|c|c|c|}
\hline Variable & Study Ia & Study $2^{b}$ & Meta-analysis \\
\hline Number of patients & 158 & 185 & 343 \\
\hline \multicolumn{4}{|l|}{ Sex } \\
\hline Male n (\%) & $54(34.2 \%)$ & 75 (40.5\%) & $129(37.6 \%)$ \\
\hline Female n (\%) & $104(65.8 \%)$ & 110 (59.5\%) & $214(62.4 \%)$ \\
\hline Age in years, median (max-min) & $69(37-88)$ & $63(23-84)$ & $67(23-88)$ \\
\hline Primary open-angle glaucoma $\mathrm{n}(\%)$ & $109(69.0 \%)$ & $183(98.9 \%)$ & $292(85.1 \%)$ \\
\hline Pseudoexfoliative glaucoma n (\%) & $16(10.1 \%)$ & I (0.5\%) & $17(5.0 \%)$ \\
\hline Ocular hypertension n (\%) & $33(20.9 \%)$ & I (0.5\%) & 34 (9.9\%) \\
\hline
\end{tabular}

Notes: In three patients, one eye was diagnosed with primary open-angle glaucoma and the other eye with ocular hypertension; these patients were categorized as primary open-angle glaucoma. In an additional three patients, one eye was diagnosed with primary open-angle glaucoma and the other eye with pseudoexfoliative glaucoma; these

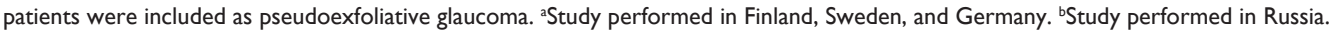

Abbreviations: max, maximum; min, minimum. 
study (between-patient effect), treatment (within-patient effect), and their interaction was fitted for the study variables. A parametric analysis method was used for IOP, conjunctival redness, tear break-up time (tBUT), and tear production (Schirmer's test), and a corresponding nonparametric analysis method was used for the remaining study variables that were tested statistically. ${ }^{23}$ As no real evidence of heterogeneity was detected between the two studies, the final analyses did not incorporate the interaction effect.

\section{Results}

All results are provided as means and standard deviations for continuous variables and frequencies and percentages (\%) for ordinal variables, unless otherwise indicated. A summary of the demographic characteristics of the study patients is displayed in Table 2. Both studies succeeded in enrolling representative samples of $\mathrm{OH} / \mathrm{OAG}$ patients with comparable distributions of age and sex. The overall mean age of the patients was 67 years (range 23-88 years). Approximately two-thirds of the patients were females (62.4\%). A majority of the patients were diagnosed with primary OAG $(85.1 \%)$ and only one-tenth with $\mathrm{OH}(9.9 \%)$ and one-20th with PEX (5.0\%). Only 27 (7.9\%) patients discontinued the studies prematurely. The most common causes of discontinuation were protocol deviation (nine patients), adverse event (nine patients), and patient request (six patients). Four of the discontinued patients did not have any postbaseline data. Consequently, the overall results are summarized for a cohort of 339 patients in the sequel.

\section{Ocular symptoms}

The frequency distributions of ocular symptoms are summarized in Table 3 by study visit. All five symptoms were prevalent at baseline with preserved latanoprost. Mildto-severe irritation/burning/stinging, foreign body sensation, tearing, itching, and dry eye sensation were reported by $59.6 \%$,

Table 3 Number (\%) of patients experiencing ocular symptoms (irritation/burning/stinging, foreign body sensation, tearing, itching, and dry eye sensation) or ocular sign (blepharitis) at baseline during treatment with preserved latanoprost and after 6 weeks and 12 weeks of treatment with preservative-free tafluprost

\begin{tabular}{|c|c|c|c|c|}
\hline $\begin{array}{l}\text { Symptoms/signs of } \\
\text { ocular surface disease }\end{array}$ & $\begin{array}{l}\text { Severity } \\
\text { grade }\end{array}$ & $\begin{array}{l}\text { Baseline preserved } \\
\text { latanoprost }(\mathbf{N}=339)\end{array}$ & $\begin{array}{l}6 \text { weeks* preservative- } \\
\text { free tafluprost }(N=3 \text { I })\end{array}$ & $\begin{array}{l}\text { I } 2 \text { weeks* preservative- } \\
\text { free tafluprost }(N=3 \text { | } 6)\end{array}$ \\
\hline \multirow[t]{5}{*}{ Irritation/burning/stinging } & None & 97 (28.6\%) & I 87 (58.8\%) & $210(66.5 \%)$ \\
\hline & Trace & 40 (I I.8\%) & 62 (19.5\%) & $53(16.8 \%)$ \\
\hline & Mild & II $3(33.3 \%)$ & $36(11.3 \%)$ & $29(9.2 \%)$ \\
\hline & Moderate & 75 (22.1\%) & $31(9.7 \%)$ & $24(7.6 \%)$ \\
\hline & Severe & $14(4.1 \%)$ & $2(0.6 \%)$ & $0(0.0 \%)$ \\
\hline \multirow[t]{5}{*}{ Foreign body sensation } & None & $166(49.0 \%)$ & $233(73.3 \%)$ & $252(79.7 \%)$ \\
\hline & Trace & 38 (I I.2\%) & 35 (I I.0\%) & $20(6.3 \%)$ \\
\hline & Mild & $76(22.4 \%)$ & $32(10.1 \%)$ & $27(8.5 \%)$ \\
\hline & Moderate & 47 (13.9\%) & $16(5.0 \%)$ & $15(4.7 \%)$ \\
\hline & Severe & $12(3.5 \%)$ & $2(0.6 \%)$ & $2(0.6 \%)$ \\
\hline \multirow[t]{5}{*}{ Tearing } & None & I 57 (46.3\%) & $222(69.8 \%)$ & $232(73.4 \%)$ \\
\hline & Trace & $44(13.0 \%)$ & $44(13.8 \%)$ & $36(11.4 \%)$ \\
\hline & Mild & $59(17.4 \%)$ & $33(10.4 \%)$ & $33(10.4 \%)$ \\
\hline & Moderate & $56(16.5 \%)$ & $17(5.3 \%)$ & $12(3.8 \%)$ \\
\hline & Severe & $23(6.8 \%)$ & $2(0.6 \%)$ & $3(0.9 \%)$ \\
\hline \multirow[t]{5}{*}{ Itching } & None & I 83 (54.0\%) & $213(67.0 \%)$ & 226 (7I.5\%) \\
\hline & Trace & 40 (I I.8\%) & $53(16.7 \%)$ & $43(13.6 \%)$ \\
\hline & Mild & 67 (19.8\%) & 35 (I I.0\%) & $30(9.5 \%)$ \\
\hline & Moderate & 38 (I I.2\%) & $15(4.7 \%)$ & 14 (4.4\%) \\
\hline & Severe & II (3.2\%) & $2(0.6 \%)$ & $3(0.9 \%)$ \\
\hline \multirow[t]{5}{*}{ Dry eye sensation } & None & III (32.7\%) & I 77 (55.7\%) & 202 (63.9\%) \\
\hline & Trace & $32(9.4 \%)$ & 61 (19.2\%) & $4 \mid(13.0 \%)$ \\
\hline & Mild & $87(25.7 \%)$ & $50(15.7 \%)$ & 49 (15.5\%) \\
\hline & Moderate & $85(25.1 \%)$ & $25(7.9 \%)$ & $22(7.0 \%)$ \\
\hline & Severe & $24(7.1 \%)$ & $5(1.6 \%)$ & $2(0.6 \%)$ \\
\hline \multirow[t]{4}{*}{ Blepharitis } & None & I 35 (39.8\%) & 195 (6I.3\%) & $208(65.8 \%)$ \\
\hline & Mild & $159(46.9 \%)$ & I I8 (37.1\%) & $105(33.2 \%)$ \\
\hline & Moderate & 44 (13.0\%) & $5(1.6 \%)$ & $3(0.9 \%)$ \\
\hline & Severe & I (0.3\%) & $0(0.0 \%)$ & $0(0.0 \%)$ \\
\hline
\end{tabular}

Notes: *The changes from baseline at 6 weeks and 12 weeks were statistically significant; $P<0.001$. 
A

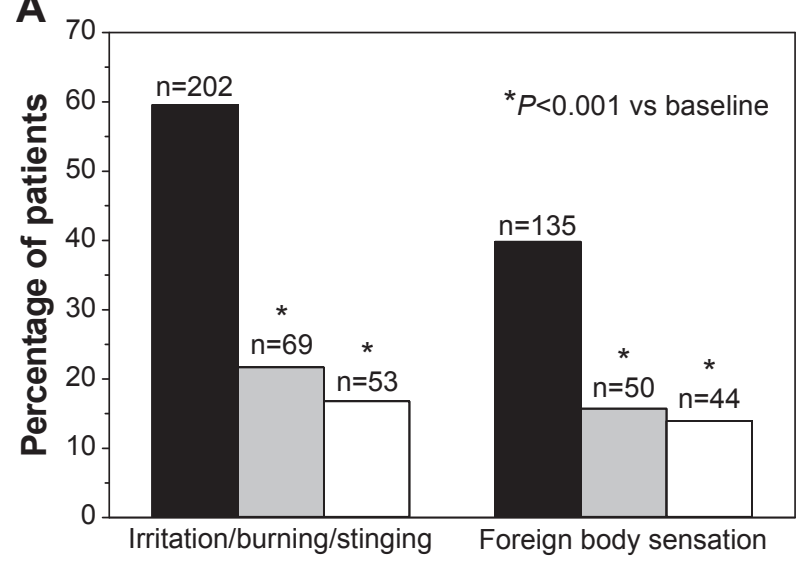

B

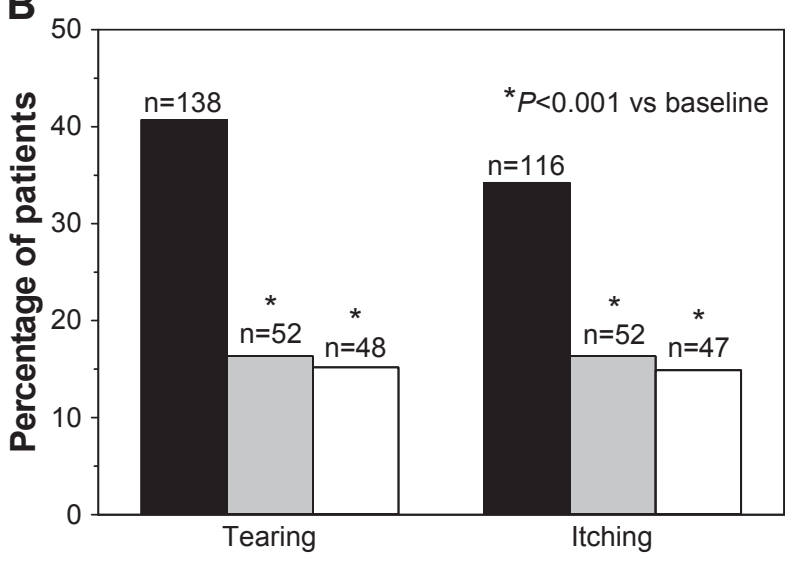

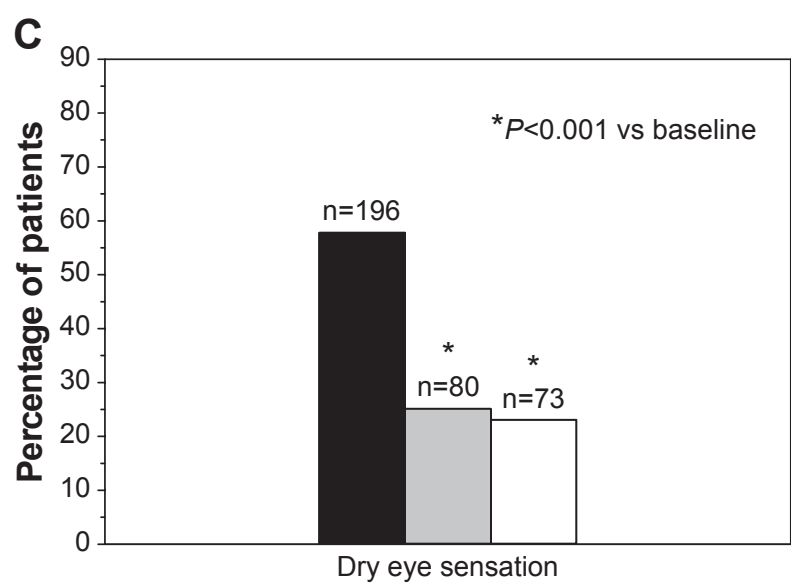

Figure I Incidence of irritation/burning/stinging and foreign body sensation (A), tearing, itching (B), and dry eye sensation (C) at baseline during preserved latanoprost treatment and at 6 weeks and 12 weeks after switching to preservative-free tafluprost treatment.

Notes: The number of patients suffering from the ocular symptom is shown above each bar, and the total number of patients per visit is shown in the box.

$39.8 \%, 40.7 \%, 34.2 \%$, and $57.8 \%$ of the patients, respectively (Figure 1). A statistically significant shift $(P<0.001)$ toward less severe symptoms was already seen 6 weeks after the switch to preservative-free tafluprost. The percentages of patients with no or only a trace of a symptom increased remarkably, and the percentages of patients with mild-to-severe symptoms decreased accordingly. A continued improvement was seen in all symptoms from 6 weeks to 12 weeks, but to a lesser extent. At the final 12-week examination, mildto-moderate irritation/burning/stinging, foreign body sensation, tearing, itching, and dry eye sensation were reported by only $16.8 \%, 13.9 \%, 15.2 \%, 14.9 \%$, and $23.1 \%$ of the patients (Figure 1). Thus, the 12-week percentages with preservativefree tafluprost were only around one-third of those reported for latanoprost at baseline.

\section{Ocular signs}

The visit-wise frequency distributions of three ocular signs are presented in Table 3 (blepharitis) and Table 4 (corneal and conjunctival fluorescein staining). Blepharitis (mild to severe), corneal fluorescein staining (grades I-IV), and combined conjunctival fluorescein staining (grades II-VIII) were reported by $60.2 \%, 82.9 \%$, and $87.9 \%$ of the patients, respectively, at baseline with preserved latanoprost (Figure 2). Ocular signs also improved significantly after the switch to preservative-free tafluprost $(P<0.001)$. The utmost severity grades became sporadic by the 12-week examination. For example, only three moderate cases of blepharitis were reported at 12 weeks. Consequently, blepharitis (mild to severe), corneal fluorescein staining (grades I-IV), and combined conjunctival fluorescein staining (grades II-VIII) were reported only by $34.2 \%, 41.8 \%$, and $50.9 \%$ of the patients at the 12 -week visit with preservative-free tafluprost (Figure 2). These percentages were only around one-half of those reported for latanoprost at baseline.

The remaining three ocular signs were evaluated on a continuous scale (as half grades were allowed for conjunctival hyperemia). The degree of conjunctival hyperemia was decreased from $1.51 \pm 0.76$ at baseline 
Table 4 Number (\%) of patients experiencing corneal or conjunctival fluorescein staining during treatment with preserved latanoprost and after 6 weeks and 12 weeks of treatment with preservative-free tafluprost

\begin{tabular}{|c|c|c|c|c|}
\hline Fluorescein staining & $\begin{array}{l}\text { Severity } \\
\text { grade }\end{array}$ & $\begin{array}{l}\text { Baseline preserved } \\
\text { latanoprost }(\mathbf{N}=339)\end{array}$ & $\begin{array}{l}6 \text { weeks* preservative- } \\
\text { free tafluprost }(N=318)\end{array}$ & $\begin{array}{l}\text { I } 2 \text { weeks* preservative- } \\
\text { free tafluprost }(\mathrm{N}=3 \text { | } 6)\end{array}$ \\
\hline \multirow[t]{5}{*}{ Cornea } & 0 & $58(17.1 \%)$ & I 44 (45.3\%) & I 84 (58.2\%) \\
\hline & I & $132(38.9 \%)$ & $132(4 \mid .5 \%)$ & 109 (34.5\%) \\
\hline & II & $125(36.9 \%)$ & $4 \mathrm{I}(12.9 \%)$ & $22(7.0 \%)$ \\
\hline & III & $22(6.5 \%)$ & $\mathrm{I}(0.3 \%)$ & $\mathrm{I}(0.3 \%)$ \\
\hline & IV & $2(0.6 \%)$ & $0(0.0 \%)$ & $0(0.0 \%)$ \\
\hline \multirow[t]{9}{*}{ Conjunctiva $^{a}$ (combined) } & 0 & $20(5.9 \%)$ & $69(21.7 \%)$ & $102(32.3 \%)$ \\
\hline & I & $21(6.2 \%)$ & 59 (I8.6\%) & $53(16.8 \%)$ \\
\hline & II & $115(33.9 \%)$ & $129(40.6 \%)$ & $108(34.2 \%)$ \\
\hline & III & $42(12.4 \%)$ & $22(6.9 \%)$ & $22(7.0 \%)$ \\
\hline & IV & $100(29.5 \%)$ & 35 (I I.0\%) & 25 (7.9\%) \\
\hline & $\mathrm{V}$ & 13 (3.8\%) & I (0.3\%) & $3(0.9 \%)$ \\
\hline & VI & $25(7.4 \%)$ & $3(0.9 \%)$ & $3(0.9 \%)$ \\
\hline & VII & $0(0.0 \%)$ & $0(0.0 \%)$ & $0(0.0 \%)$ \\
\hline & VIII & $3(0.9 \%)$ & $0(0.0 \%)$ & $0(0.0 \%)$ \\
\hline
\end{tabular}

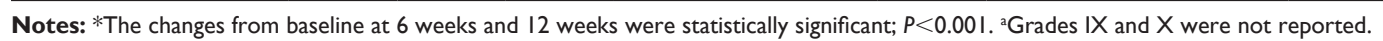

with preserved latanoprost to $0.86 \pm 0.59$ and $0.72 \pm 0.59$ at 6 weeks and 12 weeks, respectively, after the switch to preservative-free tafluprost (Table 5; $P<0.001$ at both visits). The severity of conjunctival hyperemia was thus halved over the 12-week treatment period, and the incidence of hyperemia was also clearly reduced (Figure 2). tBUT was increased from $5.9 \pm 4.5$ seconds at baseline with preserved latanoprost to $7.7 \pm 4.2$ seconds at 6 weeks with preservative-free tafluprost $(P<0.001)$ and $8.7 \pm 4.7$ seconds at 12 weeks with preservative-free tafluprost $(P<0.001)$. Tear production (Schirmer's test) was also increased significantly from $7.8 \pm 6.9 \mathrm{~mm}$ at baseline with preserved latanoprost to $10.6 \pm 8.6 \mathrm{~mm}$ and $11.5 \pm 8.4 \mathrm{~mm}$ at 6 weeks and 12 weeks, respectively, with preservative-free tafluprost $(P<0.001$ at both visits $)$.

\section{IOP reduction}

The overall mean IOP (of treated eyes) was $16.6 \pm 2.6 \mathrm{mmHg}$ at baseline with preserved latanoprost. Further reductions in IOP to $16.0 \pm 2.3 \mathrm{mmHg}$ and $15.7 \pm 2.5 \mathrm{mmHg}$ were seen at 6 weeks and 12 weeks, respectively, after the switch to preservative-free tafluprost $(P<0.001$ at both visits). The IOP-reducing effect was thus well sustained, and overall IOP decreases of 3.6\% (at 6 weeks) and 5.4\% (at 12 weeks) were achieved with preservative-free tafluprost relative to the baseline (preserved latanoprost).
A

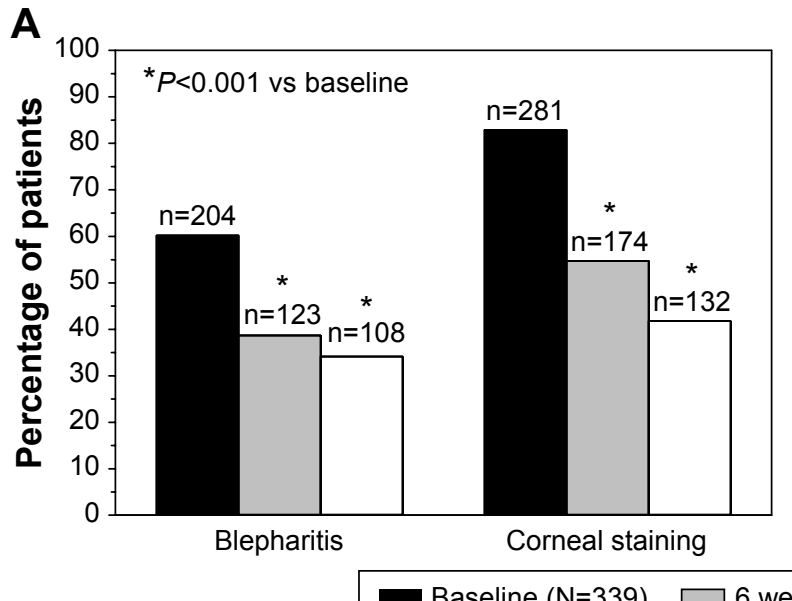

B

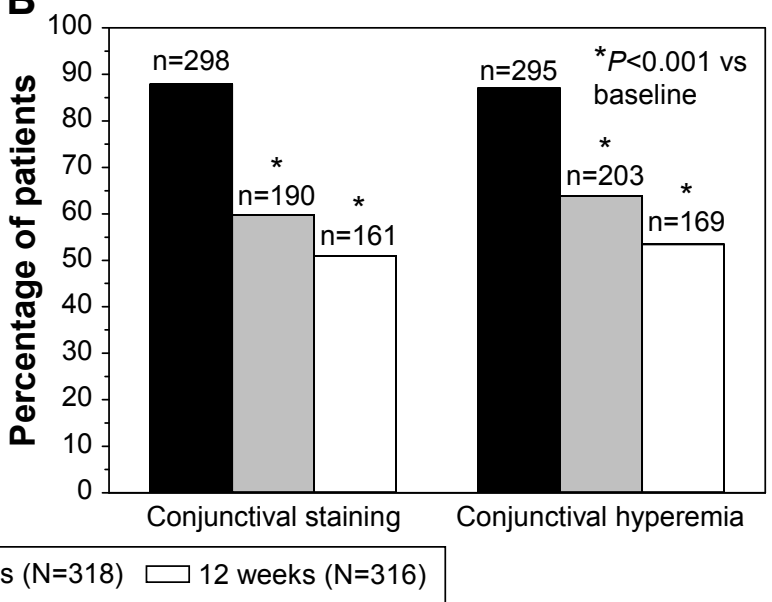

Figure 2 Incidence of blepharitis, corneal staining (A) and combined conjunctival staining and conjunctival hyperemia (B) at baseline during preserved latanoprost treatment and at 6 weeks and 12 weeks after switching to preservative-free tafluprost treatment.

Notes: The number of patients suffering from the ocular sign is shown above each bar, and the total number of patients per visit is shown in the box. 
Table 5 Degree of conjunctival hyperemia during treatment with preserved latanoprost and after 6 weeks and 12 weeks of treatment with preservative-free tafluprost

\begin{tabular}{lllll}
\hline Visit & Treatment & N & Absolute $^{\mathrm{a}}$ & Change $^{\mathrm{a}, *}$ \\
\hline Baseline & Preserved latanoprost & 339 & $1.51 \pm 0.76$ & - \\
6 weeks & Preservative-free tafluprost & 318 & $0.86 \pm 0.59$ & $-0.64 \pm 0.79$ \\
12 weeks & Preservative-free tafluprost & 316 & $0.72 \pm 0.59$ & $-0.78 \pm 0.82$ \\
\hline
\end{tabular}

Notes: aMean \pm SD for conjunctival hyperemia scale (with half grades allowed) and the corresponding changes from baseline. *The changes from baseline at 6 weeks and 12 weeks were statistically significant; $P<0.00$ I.

Abbreviation: SD, standard deviation.

\section{Drop discomfort and treatment preference}

A majority of the patients suffered from drop discomfort at baseline with preserved latanoprost. Specifically, $42 \%$ of the patients experienced mild discomfort, $31 \%$ moderate discomfort, and $1 \%$ severe discomfort, whereas only $\sim 25 \%$ of the patients experienced no discomfort at all. Conversely, $22 \%$ of the patients experienced mild discomfort, $2 \%$ moderate discomfort, and $76 \%$ no discomfort after 12 weeks treatment with preservative-free tafluprost. The improvement was statistically significant $(P<0.001)$. Furthermore, most of the patients clearly preferred preservative-free tafluprost over preserved latanoprost: up to $72 \%$ of the patients were in favor for tafluprost and only $6 \%$ for latanoprost when medication preference was evaluated as part of QoL assessments (Figure 3).

\section{Adverse events and ocular safety}

A small number of treatment-related ocular adverse events (other than the symptoms and signs summarized in the Ocular symptoms and Ocular signs sections) were reported during

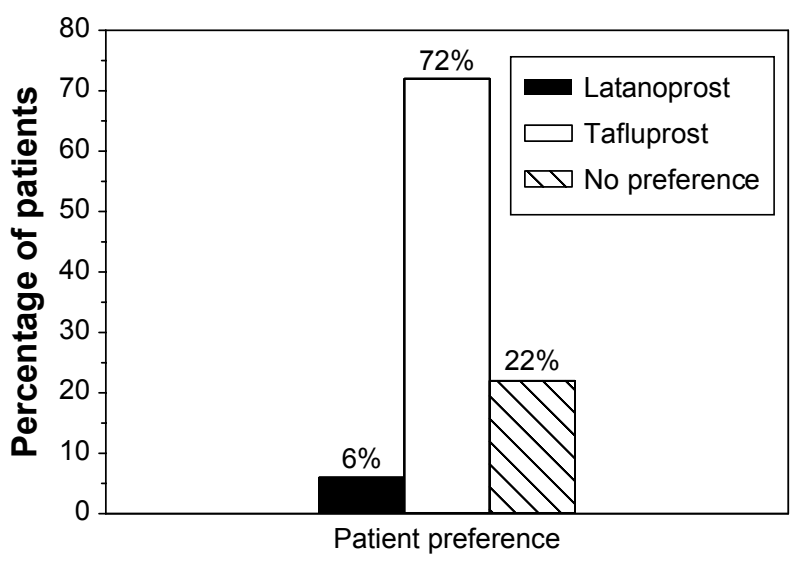

Figure 3 Patient preference on treatment options at 12 weeks.

Notes: All patients were treated with preserved latanoprost up to baseline. At baseline, their treatment was switched to preservative-free tafluprost for 12 weeks. the 12 -week period with preservative-free tafluprost. Only nine patients (2.6\%) discontinued the studies due to adverse event(s). The majority of the events were treatment related and ocular. In particular, one of the discontinued patients experienced iritis and keratitis in the study conducted in Russia. The most prevalent nonocular adverse event was headache. Only five serious adverse events were reported, of which all were nonocular and not related to the treatment. At 12 weeks, adverse events (including ocular symptoms and signs) had no impact on QoL in $72 \%$ of the patients treated with preservative-free tafluprost. The corresponding figure with preserved latanoprost at baseline was only $36 \%$.

Significant changes in visual acuity or visual fields that could be attributed to the treatment with preservative-free tafluprost were not seen. Moreover, no pathological changes were seen in either biomicroscopy or ophthalmoscopy.

\section{Discussion}

The rationale of this study was to investigate whether glaucoma patients who exhibit diminished ocular tolerability to BAC-preserved prostaglandin treatment with latanoprost would benefit from switching to a preservative-free prostaglandin treatment with tafluprost. A meta-analysis of two large Phase IIIb clinical trials - adopting essentially the same study protocols - was carried out to investigate this subject.

Evidence of BAC-induced toxicity on ocular surface has accumulated in recent years. BAC has shown to be toxic to both microorganisms and mammalian cells; hence, it may be associated with the surface side effects of a variety of eye drops. ${ }^{4-8,10,11}$ The detrimental effect of BAC is further accentuated when many different eye drops preserved with BAC are used together, a situation that is quite frequently encountered in glaucoma treatment. Therefore, the emergence of a new generation of BAC-free antiglaucoma medications (or antiglaucoma medications with negligible concentrations of BAC) is extremely important. . $^{2425}$

It has been further stated that BAC - through its detergent activity - would enhance the effectiveness of some drugs by facilitating their penetration into the eye and delivery to the cornea. Undeniably, the meta-analysis results confuted this obsolete claim. Equal IOP-lowering efficacy was demonstrated between the two prostaglandin analogs, preservativefree tafluprost and BAC-preserved latanoprost. In fact, a slight further decrease in IOP was seen with preservative-free tafluprost compared with preserved latanoprost $(\sim 1 \mathrm{mmHg}$ at week 12). 
Considerable alleviation of all ocular symptoms and signs was seen during the studies after the switch from BAC-preserved latanoprost eye drops to preservative-free tafluprost eye drops. Naturally, only a subset of the symptoms and signs was reported by a single patient at baseline while on latanoprost (ie, at least two symptoms or one symptom and one sign were the inclusion criteria for a patient). For example, $29 \%-54 \%$ of the patients summarized in Table 3 did not experience a specific ocular symptom at baseline with latanoprost. By concentrating solely on the patients who had at least a trace of a symptom ( $46 \%-71 \%)$, remarkable rates of improvement (of at least one class) were achieved with preservative-free tafluprost at 12 weeks: $82 \%$ for irritation/ burning/stinging, $84 \%$ for foreign body sensation, $83 \%$ for tearing, $78 \%$ for itching, and $83 \%$ for dry eye sensation. Above all, $\sim 40 \%$ of all patients were entirely symptom free at the end of the 12-week treatment period.

The severity of conjunctival hyperemia was halved during the 12-week treatment period with preservative-free tafluprost (Table 5). The hyperemic effect of latanoprost may be largely caused by the high concentration of BAC $(0.02 \%)$ in the ophthalmic solution, since no clear differences between the BAC-preserved formulations of latanoprost and tafluprost were seen for conjunctival hyperemia in a previous large, randomized, double-masked, Phase IIIb clinical trial. ${ }^{19}$ In essence, the hyperemic effect may lead to reduced treatment compliance. It may also be a sign of conjunctival inflammation. Therefore, a drug that causes less or no hyperemia is preferable.

HLA-DR-positive conjunctival epithelial cells and MUC5AC-expressing goblet cells were studied in impression cytology specimens as part of the study conducted in Finland, Sweden, and Germany. Significant changes toward normalization were seen during the treatment with preservative-free tafluprost in comparison with BAC-preserved latanoprost. ${ }^{20}$ The results suggest that preservative-free tafluprost induces less harmful effects on the conjunctiva, which is the principal target of the toxic effects of topical ophthalmic preparations.

Patient-related outcomes indicated the superiority of preservative-free tafluprost. For example, patients' reports on drop discomfort reduced substantially during the 12-week treatment with preservative-free tafluprost. Moreover - on the basis of the QoL questionnaire (COMTol) - a clear majority of the patients (72\%) preferred preservative-free tafluprost over BAC-preserved latanoprost. The side effects had also less impact on the QoL during the treatment with preservative-free tafluprost.
Prostaglandin analogs have progressively replaced beta-blockers as the first-line therapy of $\mathrm{OH} / \mathrm{OAG}$, because they are the most effective IOP-lowering agents, lack relevant systemic side effects, and require only once-daily dosing. ${ }^{25,26}$ Preservative-free prostaglandin analogs - such as tafluprost minimize the risk of ocular side effects and increase the likelihood of good treatment adherence. Hence, preservative-free solutions should be considered when available. They could be particularly beneficial to patients who 1) have preexisting ocular surface disease, 2) are expected to develop ocular surface disease (dry eye) during long-term medication, 3) are using multiple concomitant topical ocular treatments, and/or 4) are about to undergo glaucoma surgery. ${ }^{27,28}$ In general, the current glaucoma treatment guidelines call for therapies that can maintain visual function, minimize side effects, increase adherence, and improve QoL of the patients. A correct choice of first-line therapy is fundamental to achieving these patient outcomes and reducing the economic costs in the long run. Preservative-free prostaglandin analogs currently provide the best monotherapy option for first-line treatment of $\mathrm{OH} / \mathrm{OAG}$. The costs of disease management could even be halved, if $\mathrm{OH} / \mathrm{OAG}$ is prevented/delayed effectively. ${ }^{29}$

The studies included in the meta-analysis were limited by their open-label designs. An open-label design could not be avoided, since commercial BAC-preserved latanoprost was available only in conventional eye drop bottles and preservative-free tafluprost in unit dose dispensers. The studies were not designed to mitigate the effect of regression to the mean (RTM) either. In other words, patients initially identified by high values could have lower values on remeasurement even in the absence of an intervention. A randomized, controlled study would have been the obvious choice to control the possible bias caused by RTM. Instead of RTM, the further decrease in IOP with preservative-free tafluprost could be attributed to improved treatment compliance achieved by better tolerance. Furthermore, the limited 12-week duration of the studies did not allow for investigation of the long-term effects.

\section{Conclusion}

The present meta-analysis confirmed that preservativefree tafluprost eye drops offered clinical benefits to $\mathrm{OH} /$ OAG patients that outweighed those of the BAC-preserved latanoprost eye drops. The IOP-lowering efficacy was sustained (or even slightly improved) after replacing preserved latanoprost with preservative-free tafluprost. In addition, preservative-free tafluprost significantly decreased the symptoms and signs of ocular surface disease and 
outrated preserved latanoprost in drop comfort and treatment preference.

\section{Acknowledgments}

The authors would like to thank Oy 4Pharma Ltd, Finland especially Jouni Vuorinen for writing assistance and Teppo Huttunen for performing the meta-analysis. Study performed in Finland, Sweden, and Germany. Investigators in Finland: Kai Kaarniranta, Markku Leino, Päivi Puska, Hannu Uusitalo. Investigators in Sweden: Enping Chen, Elina Palmgren. Investigators in Germany: Thomas Hamacher, Günter Hofman, Gernot Petzold, Tobias Riedel, Ulrich Richter, and Martin Winter. Study performed in Russia: Yuriy Sergeevich Astakhov, Ernest Vitalyevich Boiko, Alexander Victorovich Doga, Evgeniy Alexeevich Egorov, Olga Alexandrovna Kiseleva, Alla Alexeevna Ryabtseva, and Vladimir Pavlovich Sergeev. The authors received editorial and writing support in the preparation of this manuscript, funded by Santen Oy, Tampere, Finland. The authors were fully responsible for the text, data, and editorial decisions for the paper. The manuscript has not been presented at any meetings.

\section{Disclosure}

Auli Ropo is an employee of Santen Oy. The authors were investigators in the respective studies in Europe and Russia and received funding from Santen Oy for the study. The authors report no other conflicts of interest in this work.

\section{References}

1. Erb C, Gast U, Schremmer D. German register for glaucoma patients with dry eye. I. Basic outcome with respect to dry eye. Graefes Arch Clin Exp Ophthalmol. 2008;246:1593-1601.

2. Rossi GC, Tinelli C, Pasinetti GM, Milano G, Bianchi PE. Dry eye syndrome-related quality of life in glaucoma patients. Eur J Ophthalmol. 2009;19:572-579.

3. Fechtner RD, Godfrey GD, Budenz D, Stewart JA, Stewart WC, Jasek MC. Prevalence of ocular surface complaints in patients with glaucoma using topical intraocular pressure-lowering medications. Cornea. 2010; 29:618-621.

4. Pisella PJ, Pouliquen P, Baudouin C. Prevalence of ocular symptoms and signs with preserved and preservative free glaucoma medication. $\mathrm{Br}$ J Ophthalmol. 2002;86:418-423.

5. Jaenen N, Baudouin C, Pouliquen P, Manni G, Figueiredo A, Zeyen T. Ocular symptoms and signs with preserved and preservative-free glaucoma medications. Eur J Ophthalmol. 2007;17:341-349.

6. Steuhl KP, Knorr M, Frohn A, Thiehl HJ. The influence of topically applied anti-glaucomatous eye drops on conjunctival cell differentiation. Fortschr Ophthalmol. 1991;88:865-869.

7. Schwab IR, Lindberg JV, Gioia VM, Benson WH, Chao GM. Foreshortening of the inferior fornix associated with chronic glaucoma medications. Opthalmolology. 1992;99:197-202.

8. Broadway DC, Grierson I, Hitchings RA. Adverse effects of topical antiglaucomatous medications on the conjunctiva. Br J Ophthalmol. 1993; 77:590-596.
9. Broadway DC, Grierson I, O’Brien C, Hitchings RA. Adverse effects of topical antiglaucomatous medications II: the outcome of filtration surgery. Arch Ophthalmol. 1994;112:1446-1454.

10. Baudouin C, Pisella PJ, Fillacier K, et al. Ocular surface inflammatory changes induced by topical antiglaucomatous drugs: human and animal studies. Ophthalmology. 1999;106:556-563.

11. Pisella PJ, Debbasch C, Hamard P, et al. Conjunctival proinflammatory and proapoptotic effects of latanoprost and preserved and unpreserved timolol: an ex vivo and in vitro study. Invest Ophthalmol Vis Sci. 2004;45: $1360-1368$.

12. Boimer R, Birt CM. Preservative exposure and surgical outcomes in glaucoma patients: the PESO study. J Glaucoma. 2013;22:730-735.

13. Nakajima T, Matsugi T, Goto W, et al. New fluoroprostaglandin $F_{2 \alpha}$ derivatives with prostanoid FP-receptor agonistic activity as potent ocular-hypotensive agents. Biol Pharm Bull. 2003;26:1691-1695.

14. Takagi Y, Nakajima T, Shimazaki A, et al. Pharmacologic characteristics of AFP-168 (tafluprost), a new prostanoid receptor FP agonist, as an ocular hypotensive drug. Exp Eye Res. 2004;78:767-776.

15. Hamacher T, Airaksinen J, Saarela V, Liinamaa MJ, Richter V, Ropo A. Efficacy and safety levels of preserved and preservative-free tafluprost are equivalent in patients with glaucoma or ocular hypertension; results from a pharmacodynamics analysis. Acta Ophthalmol Suppl (Oxf). 2008; 242:14-19.

16. Sutton A, Gilvarry A, Ropo A. A comparative placebo-controlled study of prostanoid fluoroprostaglandin receptor agonist tafluprost and latanoprost in healthy males. J Ocul Pharmacol Ther. 2007;23:359-365.

17. Sutton A, Gouws $P$, Ropo A. Tafluprost a new potent prostanoid receptor agonist: a dose-response study on pharmacodynamics and tolerability in healthy volunteers. Int J Clin Pharmacol Ther. 2008;46:400-406.

18. Uusitalo H, Kaarniranta K, Ropo A. Pharmacokinetics, efficacy and safety of preserved and preservative-free tafluprost in healthy volunteers. Acta Ophthalmol Suppl (Oxf). 2008;242:7-13.

19. Uusitalo H, Pillunat LE, Ropo A. Efficacy and safety of tafluprost $(0.0015 \%)$ versus latanoprost $(0.005 \%)$ eye drops in open-angle glaucoma and ocular hypertension: 24-month results of a randomized, double-masked phase III study. Acta Ophthalmol. 2010;88:12-19.

20. Uusitalo H, Chen E, Pfeiffer N, et al. Switching from a preserved to a preservative-free prostaglandin preparation in topical glaucoma medication. Acta Ophthalmol. 2010;88:329-336.

21. Egorov EA, Astakhov YuS, Erichev VP, et al. [Evaluation of efficacy and safety of preservative-free tafluprost $0.0015 \%$ eye drops in patients with open-angle glaucoma and ocular hypertension]. RMJ Clin Ophthalmol. 2015;16:1-6. Russian.

22. Barber BL, Strahlman ER, Laibovitz R, Guess HA, Reines SA. Validation of questionnaire for comparing the tolerability of ophthalmic medications. Ophthalmology. 1997;104:334-342.

23. Pocock SJ. Clinical Trials - A Practical Approach. Chichester: John Wiley \& Sons; 1983:110-122.

24. Niwano Y, Iwasawa A, Ayaki M. Ocular surface cytotoxicity and safety evaluation of tafluprost, a recently developed anti-glaucoma prostaglandin analog. Ophthalmol Eye Dis. 2014;6:5-12.

25. European Glaucoma Society. Terminology and Guidelines for Glaucoma. 4th ed. Savona: PubliComm; 2014:141-142.

26. Boland MV, Ervin AM, Friedman DS, et al. Comparative effectiveness of treatments for open-angle glaucoma: a systematic review for the U.S. Preventive Services Task Force. Ann Intern Med. 2013;158:271-279.

27. Baudouin C. Detrimental effect of preservatives in eyedrops: implications for the treatment of glaucoma. Acta Ophthalmol. 2008;86: 716-726.

28. Bagnis A, Papadia M, Scotto R, Traverso CE. Current and emerging medical therapies in the treatment of glaucoma. Expert Opin Emerg Drugs. 2011;16:293-307.

29. Denis P. Adverse effects, adherence and cost-benefits in glaucoma treatment. Eur Ophthal Rev. 2011;5:116-122. 


\section{Publish your work in this journal}

Clinical Ophthalmology is an international, peer-reviewed journal covering all subspecialties within ophthalmology. Key topics include: Optometry; Visual science; Pharmacology and drug therapy in eye diseases; Basic Sciences; Primary and Secondary eye care; Patient Safety and Quality of Care Improvements. This journal is indexed on

Submit your manuscript here: http://www.dovepress.com/clinical-ophthalmology-journal
PubMed Central and CAS, and is the official journal of The Society of Clinical Ophthalmology (SCO). The manuscript management system is completely online and includes a very quick and fair peer-review system, which is all easy to use. Visit http://www.dovepress.com/ testimonials.php to read real quotes from published authors. 